\title{
Improving Teaching and Learning at Universities- the Use of Knowledge management
}

\author{
http://dx.doi.org/10.3991/ijac.v7i1.3590 \\ Dalal Mohammad Al- Zoubi \\ Albalqa Applied University, Irbid, Jordan
}

\begin{abstract}
Investment in universities is a long term investment, requiring the adoption of an effective management system like the KM system. The implementation of $\mathrm{KM}$ framework in universities has become an apparent phenomenon in the age of globalization, accelerating technological change, and increased competition. Therefore, this paper aims to come up with a vision for the successful use of KM applications in teaching and learning at universities. This can be done by proposing an integrated framework to regulate the use of KM at all administrative and educational levels of the university, and show the factors affecting the successful use of KM to improve the learning outcomes.
\end{abstract}

Index Terms-Knowledge management, learning outcomes, teaching \& learning.

\section{INTRODUCTION}

Universities are the main instruments of society for the constant pursuit of knowledge. Knowledge management in educational settings should provide a set of designs for linking people, processes, and technologies and discuss how organizations can promote policies and practices that help people share and manage knowledge [1].

The university is a scientific and intellectual center resorted to in order to solve the most difficult problems facing society. It is also credited for technology innovation and highly qualified personnel. Basically, Its activity is academic, the direct output of which is thought and knowledge which are subject to different principles in terms of production and marketing compared with those of other institutions [2].

The investment in this field is a long-term investment requiring the adoption of an effective management system like knowledge management (KM) system. So, the university can shift from managing teaching staff and students to managing knowledge and innovation to achieve their goals [3].

Educators at universities are prime examples of knowledge workers because they typically have considerable personal discretion and responsibility in analyzing, developing, and implementing their curricular goals. The most exciting part about applying these ideas is that the primary 'customers' - the learners - can also become an integral part of the university, as they can play a critical role in helping to create and share knowledge throughout the system. Thus, in universities, learners need not simply be perceived as passive 'customers', but can rather become knowledge workers themselves, playing a unique role in producing and managing knowledge within the university. One of the key challenges posed by the advent of the knowledge economy is to develop the role of educa- tors and learners as knowledge workers within broader, integrated education systems [4].

Universities, are knowledge-oriented and they reflect excellence. They are the solid ground for assuming principles and practice of KM, which are enthusiastically adopted by the business world [5]. These principles could be applied to universities with equal success chances [6]. So, universities should seek to aim at the discovery and dissemination of new and useful knowledge which is a vital issue, and to be among the first institutions to implement KM practice. Nevertheless, universities have been slow in KM practices [7].

Thus, the implementation of KM frame work in universities has become an apparent phenomenon in the age of globalization, accelerating technological change, and increased competition $[8,9]$.

Therefore, this paper aims to come up with a vision for the successful use of KM applications in teaching and learning at universities. This can be done by proposing an integrated framework to regulate the use of KM at all administrative and educational levels of the university and show the factors affecting the successful use of KM to improve the learning outcomes.

The importance of this subject stems from situation where the use of KM in universities is still in need for further research and study. This is because KM system, one of modern management systems, has not been adopted and applied in this sector at a large scale. Awareness of $\mathrm{KM}$ is still in its infancy at universities compared with its status in the business sector.

It is expected that this paper adds some information about the concept of KM in general and its use in teaching and learning in particular. Some universities would benefit from the framework of the use of KM proposed. The paper also emphasizes the need for continuation of research on how universities can benefit from $\mathrm{KM}$ in managing its affairs.

\section{KM AND UNIVERSITY}

Knowledge is power and wealth at the same time. The power of knowledge characterizes the twenty first century as it is the most important source which has been built accumulatively and does not decrease through use [10].The increased importance of knowledge in the process of production is evident in the debate regarding the type of knowledge that is deemed to be most important to economic creations [11].

The knowledge management system is the framework of an integration of organizational elements in organizational culture, organizational information technology in- 
frastructure and the organization's store of individual and collective experiences, learning, insights, values, etc.. Members can effectively accomplish organizational goals through knowledge management processes and procedures. An organization that effectively manages knowledge is likely to be considered a learning organization. Knowledge dissemination and responsiveness to knowledge are cited repeatedly as the most effective way to a competitive advantage. While the need for effective managing of knowledge is accepted, much of the literature continues to explore measurement and its effect on outcomes [1].

Tremendous changes are taking place in advanced industrial societies, as a result of intended and unintended consequences of economic and technological development. The educational sector is not an exception from such changes, since relevant development pose several challenges for the transformation of the whole educational process, including educational curricula, learning materials, instructional practices and education stakeholders [11].

In the education sector, it is of great advantage for the different institutions to know how to manage information in order to achieve their goals, accomplish their mission, deliver their services and cope with change. Particularly, within the context of teaching and learning systems, KM efforts can help both teachers and students to share valuable insights with each other, to reduce redundant work, to practice self-paced learning, to undertake research using, among others, archival data/information and to embark on reflective practice for promoting ongoing personal and professional development [12].

Cross and Baird (2000) [8,6] identifies five types of knowledge commonly used in organization. The first type is that embedded in the mind of individuals, and is gained through working experience, research, teaching, and operational activities. The second kind is knowledge presented in work group, such as consensus on work rules. The third kind is knowledge that has been documented and organized for use, such as course syllabi or data malls. The fourth kind is knowledge that is embedded in organizational process, like laboratory exercises. The fifth kind is embedded in products and services, such as the skills of graduating students, patents, or research publication, each type of knowledge can be used to achieve organization missions and goals.

Some writers stress that scientific knowledge is the most important kind, other writers argue that organizations must exploit the tacit knowledge and information held by workers, while Reich (1991) suggests that economic progress will involve the combination of scientific and tacit knowledge [11].

KM has four major strands that can be used to categories KM projects as follows: [13]

1. The creation of knowledge repositories or knowledge banks which draw together all the explicit knowledge in the organization, which can be shared with others.

2. Approaches and tools that promote access to knowledge, internet, extranet... etc.

3. Knowledge- based culture, in which the senior management establishes expectation about the sharing of knowledge (policy statement, job descriptions... etc).
4. Valuing knowledge as an asset or the intellectual capital strand of KM is important in developing the fact that knowledge is a key resource.

The KM literature suggests that re-use of externalized knowledge is fundamental for improved efficiency, reduced cost and dependency on individuals know-how, rather than considering knowledge as a specific thing, explores the relationship between knowledge and the work that people do [14]. This leads to the learning organization which is an organization that facilitates individual and organizational learning in such a way so as to support success in responding to continuing change [13].

Universities are widely regarded not only as teaching establishments, but also as organizations that create new knowledge and support social communities. KM is usually recommended as one of the important roles to improve efficiency and effectiveness of university mandate and provide many benefits to university [15]. The strength and weaknesses of knowledge strategy dominating the contemporary university are related to the loss of information that occurs by abstracting whatever to be studied from an unmanageable complex reality, to place it in the simpler and manageable context of a discipline or profession [16].

According to Butcher (n.d), it is possible to extract a set of principles that should inform the implementation of a knowledge management strategy as follows:

1. Start with a Strategy.

2. Involve users in the design of the knowledge management strategy and systems.

3. Clearly distinguish knowledge management strategies from technology implementation and information systems management.

4. Ensure that the broader organizational environment supports and rewards creation and sharing of knowledge.

5. Approach knowledge management as an iterative process.

6. Measure the impact of knowledge management. [4].

Teaching is a core activity of any university, but there is an enormous pressure of academics to undertake research either through publication or undertaking research degree, and little attention is given to assisting with the philosophy and implementation of good teaching practices [17].

The quality of education is a matter of concern at all levels of society. This places a responsibility on educators and educational administrators to demonstrate that their educational institutions-a pre-school educational facility, a school district, a university, all of which are capable of providing high quality educational opportunities at a reasonable cost [18]. This means the need for a modern management system like KM system to manage teaching and learning at all levels of educational institutions, especially universities.

\section{THE FRAMEWORK OF KM}

Figure (1) shows a suggested framework which regulates the use of KM in universities. This framework is based on a set of assumptions as follows:

1. The successful use of KM in university management requires a holistic integrated view of applications of the system. 
2. The use of KM in universities leads to improvement of the quality of education and learning outcomes.

3. The successful use of KM requires the involvement of academics, the management and students in this system.

4. There are factors affecting the successful use of KM by academics, management and students.

5. The successful learning outcomes are linked to the academics' success in evaluation process.

6. The outcomes of learning are the main inputs of institutions in a given society.

7. The assessment of the success of learning outcomes is identified by the feedback provided by different institutions.

Basically, the modern university comprises two cultural hemispheres, the academic and the managerial, and that bifurcation has important implications when it comes to thinking about the appropriateness of specific KM proposals and strategies. The two hemispheres of the university are populated, respectively by academics and managers [6].

A study examines the reason why $\mathrm{KM}$ is apparently so unpopular in universities, results show that corporate culture and organizational structure are the major factors affecting perceptions of relevance KM programs and projects [19]. It is important to recognize that learning at universities occurs in social contexts, and that the socio- cognitive characteristics will shape approaches to knowledge creation, transfer and utilization [6]. Therefore, the as- sumption was, as noted in the figure 1, that the successful use of KM system in running the various university affairs requires an integrated view by all parties, academics, administrators, and students. The successful use is affected by the extent of awareness of this system and its applications.

$\mathrm{KM}$ awareness is defined as the extent of knowledge that the academic, administrators and students have about

$\mathrm{KM}$, its role in building the competitive advantage of the university, the way KM assets are used (tangible and intangible), the goals $\mathrm{KM}$ seeks to achieve, the benefits resulting from utilization $\mathrm{KM}$, the importance of $\mathrm{KM}$ leader, the role and contribution of the prevailing institutional culture at the university using KM [20].

The successful use of KM system also requires the ability to practice the operations linked to this system. It is defined as the extent of generating knowledge by academics, and management staff through interaction between explicit and implicit knowledge, the sharing of such knowledge among the staff and the exercise of institutional learning processes leading to innovation in KM [20]. So, individuals are necessary for the production of knowledge operations, simply because they are knowledge themselves, and they only need little information to enable them produce knowledge [21].

In a study aimed to see if some factors like KM awareness, and the practice of KM operations affecting the utilization of KM at Jordanian universities. Result confirms that there is a significant impact of KM awareness and the practice of KM operations on the utilization of KM [20].

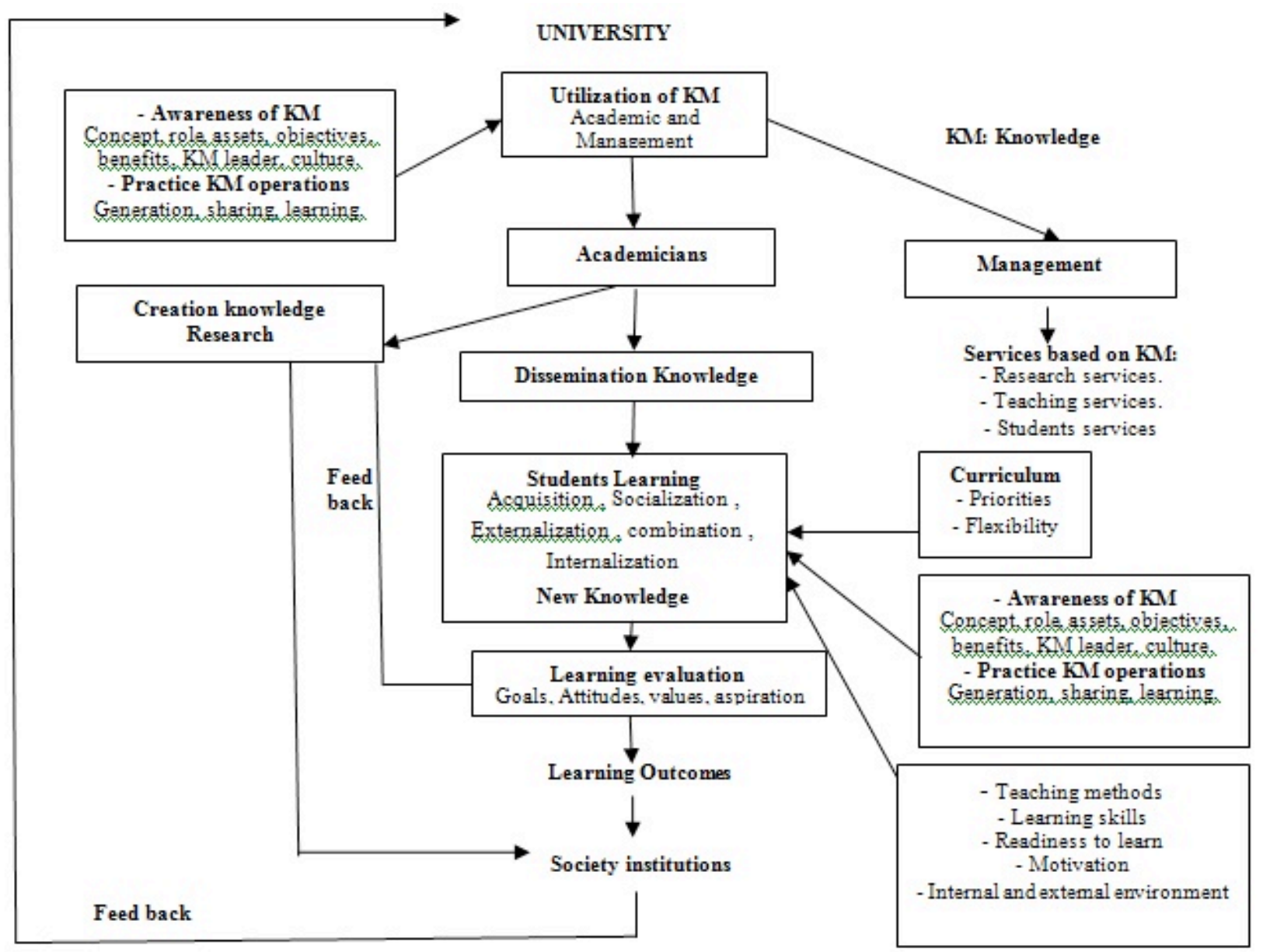

Figure 1. Framework of the Use of Knowledge Managment System at Universities 
The application and implementation of an KM system improve the quality of education at universities. An effective KM system requires every academician to practice appropriate management of knowledge in his or her teaching activities, which includes, generating, sharing, acquiring, storing and disseminating knowledge effectively to users of knowledge, especially students [22, 5].

It is suggested that there are four major processes to form a culture of knowledge sharing and collaboration. They are: (1) making knowledge visible, (2) increasing knowledge intensity, (3) building knowledge infrastructure, and (4) developing a knowledge culture. From an academic knowledge perspective, the learning community should start at the individual level, create departmental knowledge, create domains of knowledge across departments that share academic interests or disciplines, create institutional knowledge networks and networks with other institutions and corporations. The capitalization of collective knowledge begins with sharing in knowledge communities: from individual, through teams and groups, to organizations. Individual strategy mainly deals with the teacher's individual professional growth. KM helps teachers develop their teaching ability, skill and experience, and action research. Once individual knowledge is captured, institutions and processes must be established to compel its dissemination throughout the organization. Knowledge management is then escalated to the organizational level. Institutional strategy emphasizes knowledge sharing through school-based teacher education, organizational learning, sharing culture, and teacher community. Knowledge sharing is not limited to the organization. Network strategy calls for establishment of knowledge map for teaching, knowledge database and instructional resource center [1].

In a study aimed to evaluate the level of practice among the academicians and to determine factors contributing to the effectiveness of KM practices at individual, faculty and university level at eight universities in Malaysia. The result indicates that info-structure, and knowledge acquisition, generation, storage and dissemination, are important factors in shaping the KM initiatives [22].

In another study aimed to studies the role of KM in facilitating knowledge sharing among stakeholders in technical educational institutions in India and elaborates on the need for knowledge management in the teaching-learning process. A KM framework for enhancement of knowledge sharing by the use of shared intellectual repositories is proposed. The findings show that the authors value the impact that $\mathrm{KM}$ can have in enhancing the quality of teaching and learning in technical educational institutions, and underscore the need for credible research into the benefits and challenges that the implementation of ITbased KM intervention will provide [23] .

Sharing of experience and best practice for academics can be achieved by:

- building repositories of course syllabi.

- Providing pointers to evaluation of different pedagogic styles and practices

- Highlighting lessons from distance education experiments.

- Creating online forums, or communities of practice, for the exchange of tacit knowledge and on the job experiences [6].
In describes the main informative products of university information services, emphasizing the use of web technology for building corporate portals, evaluated as the core of the organization and sharing of knowledge in universities [24].

At universities there are two branches of knowledge: scientific knowledge, and practical knowledge. Scientific knowledge is explicit and clear through education, research publishing, and conferences, it moves within the university through the integration of students in learning processes and the scholars studies of the research results, cooperation between universities and the labor market. In contrast, the practical knowledge is the support provided by workers, which generates explicit knowledge in areas such as computer services, management, research support, and student services $[25,8]$.

Scientific research is the core of higher education and it can be called "knowledge generation". It is clear that research is the real contribution of the university in knowledge community. The distinguishing feature of the university is the link between research and teaching where the research should have direct and changing impact on teaching.[5]. Suggested KM applications relating to research include building publicly accessible repositories of scholarly expertise and interest, to promote transparency and information exchange [6].

Much of the KM literature focuses on ways to increase the volume of knowledge available, ensure its quality, and improve its accessibility. Access to other expertise, experience, insights, and opinion is termed knowledge sourcing, which is one of many learning behaviors ; they fall into two categories: Individuals can learn from own experience or from the experiences of others, three generic forms of knowledge sourcing namely: one- to- one, oneto- many, or many- to- many. Examples include one- toone conversation via telephone, email, or in persons. Examples include one-to- many, accessing a document that has been stored in a knowledge repository, printed in a book, or posted on an internet. Examples include many-tomany, communication via electronic discussion groups or face to face meetings [26].

The teaching process in student-oriented universities should lead to successful learning, which requires that university professors should concentrate on the learning process itself and its mechanisms represented by acquisition, socialization, externalization, combination, internalization, to produce new knowledge.

The learning process is influenced by a variety of factors, such as the curriculum in terms of priority of issues it addresses, flexibility in dealing with these issues, as well as students' awareness and their practice of operations associated with KM in their learning. The learning process is also affected by the teaching methods used by teachers, learning skills possessed by students which affected by cultural differences of a more diverse student body, students desire for a more participatory, experiential learning experience, and the need now and in the future for students to be able to synthesize vast amounts of rabidly updated, and therefore changing information [27]. The learning process is also affected by readiness and motivation for learning among students, as well as the climate that prevails in the learning environment.

The teachers need to have an open mind, designs teaching/learning environments which optimize the construc- 
PAPER

tion and discovery of knowledge, facilitates active learning and transfers conceptual networks to students, as needed.

They identify the emergence of individual and collective patterns and forks that arise from the interaction of different elements in the teaching/learning process (teachers, students, contents, projects, disciplines, cultures, context, etc), and adopt the required pedagogical measures to be able to manage instability and uncertainty through the implementation of strategies to face each new problem.

They provide diverse tools and didactic resources to optimize learning according to the situation, to bring students to a state of cognitive efficiency that facilitates integration, transformation and application of knowledge into creative processes and innovative solutions [28].

They possess effective and assertive communication skills, and exercise an adequate emotional and social intelligence providing empathy and motivation to the

student. They possess knowledge and expertise in the discipline. Therefore, the teacher is a mediator for the teaching/learning processes who facilitates the student the realization of his potential. However, even as a dynamic enabler of innovation, they can also become a barrier, when lacking the required training and skills.

Teachers found out that traditional methods of organization are not compatible with vast amount of digital resources available. Therefore, teachers need a KM tool that can integrate multiple types of resources, be flexible, can easily be searched, and has a user- friendly interface [29]. These tools enable students and teachers to process the information available to them and share their insights without mediation or censorship by others, so that they can not only make sense of information from elsewhere in the world, but also put it to immediate and possibly novel use. The adoption of such tools, for example, peer-to-peer learning becomes an important complement to formal teaching, giving communities far wider access to mentors across the world, drawn from higher education generally [30].

Effective $\mathrm{KM}$ is contingent upon the explication of a deep and shared understanding of the learning and teaching process. The most important transactions in education are those related to learning and teaching which are frequently the least explicated. Further, where such explication does occur, it is rarely specific enough to generate the kind of meaningful data required to make timely improvements in the learning experience of individual students [31]. Several skills and abilities needed to manage knowledge and to deal with information such as:

- Relative and organized knowledge.

- Solve complex problems.

- Collaborate, exchange knowledge, work with experts.

- Communicate, give persuasive presentation.

- Construct knowledge products.

- Integrate and critically evaluate knowledge.

- Identify and evaluate secondary effects [32].

Pintrich (1994) compared several taxonomies of learning components, and concluded that the common elements were student knowledge base, procedural skills, self- regulation of learning, and motivation and effect. The distinction between cognitive, meta cognitive, and affective mo- tivational components of learning can also be found in the work of several other researchers [33].One of the main sources of student learning is the interaction with the teacher in classroom. In fact, the teachers' contribution to student knowledge is, arguably, the most important source of learning (other sources include self- learning through reading a text- book, or through a peer study group, for example). The teacher- student "knowledge transfer" process is measured by a student performance on homework assignments, midterm, and final exam [18].

Teachers' work activities include teaching, preparation, administration, in- service/ professional development, and other activities with teaching requiring the most time. Lesson planning, constructing and grading tests take a great deal of time. The rapid changes of technology complicates the effective delivery of efficient instruction to students, and teachers have to stay current in their field, and this means taking time out to attend in- service/ professional development [34,33].

At the university of western Sydney, the foundations of university learning and teaching program is offered to all new full time teaching staff. The key aspect of the program is to enhance their ability to structure an effective learning environment for students. In this regard the program states that its strategies are collaborative, emphasizing negotiated learning, working in collegial group, and pairs, and the sharing of experiences.

The Program aims to: value the diversity of student experiences, appreciate the ways in which student learn, design effective learning experiences fore students, use appropriate presentation techniques and information and communications technology to support teaching and learning, justify appropriate strategies for assessing student learning, value and share individual and colleagues experiences and knowledge of learning and teaching [17].

In a case study about how a wiki technology was used to support collaborative activities in a KM class graduatelevel information systems and technology school, findings suggests that wikis can support collaborative knowledge creation and sharing in an academic environment. Success in attempts to provide such support may depend on: familiarity with wiki technology, careful planning for implementation and use, appropriate class size, and motivations of student to engage in discovery learning [35].

While under a design thinking paradigm, student would be encouraged to think broadly about problems, develop a deep understanding of issues, and plan a process to implement a good idea [36].

The use of small cases can be used to engage the student in an interactive learning experience that requires grappling with difficult issues and formulating well reasoned analysis for problems posed. The objective of a mini cases is to broaden, the thinking of students by raising difficult, focused questions [37].

Social constructivist teaching methods, such as problem- based learning, case- based instruction or collaborative research projects, require students to construct or create knowledge proactively by engaging with realistic problems. Three rationales for adopting social constructivist teaching methods in pre- professional undergraduate programs are that they may: 1- help student to construct a deeper understanding of the theoretical concepts that is better connected with practical experience, 2- help students to develop skills in performing the routine problem- 
PAPER

solving tasks of their intended profession, 3- develop students knowledge creation capacity [24]. Results of a study of the social constructivist teaching methods found that lecturers perceive association between the use of social constructivist teaching methods and the superior development of their students profession- specific skills and knowledge creation capacity [38].

Teaching functions refer to those functions that promote high quality student learning. The effective function refer to creating and maintaining a positive motivational and emotional climate for learners [33]. Many authors argue that active learning include:

- learning the content and improving the student skills of verbal delivery.

- Feedback which is essential in learning, Instead of providing feedback on the students actual performance, feedback should be about growth rather than grading.

- The ability to work effectively in a team/ group in higher education, then educators must develop student skills as cooperation and collaboration, resolving conflict negotiating, problem solving, critical thinking, and others.

- Motivation: The authors raise the issues of three types of motivation, namely, goal types, sources of enjoyment and general motivation to learn, as well as the four motivational conditions of interest, relevance, expectancy and satisfaction [39]. In a survey of 252,080, 1997 freshmen students at 464 two-and four-years institutions found that, in comparison to those surveyed 10 years ago, today's freshmen were more bored in class, more often overslept and missed classes or appointments, and were less likely to study or do homework six or more hours a week [27]. This findings emphasizes the importance of motivation in learning.

Teachers' evaluation of students' learning is the real indicator of successful teaching outcomes which enable students to get adapted and be in harmony with various institutions in the society. The importance of measuring performance in higher education has long been understood by all Stakeholders including teachers, students, administrators, and researchers [18].

Teaching / learning and evaluation are inextricably linked and it is virtually impossible to improve teaching without understanding its impact. Why does evaluation often get put on the back burner? Perhaps part of the answer can be attributed to a fairly common perception that doing evaluation requires a certain level of expertise in evaluation methodologies and data analysis. Another part of the answer might relate to the complexity of the task, learning is complex and multidimensional, and any serious attempt to evaluate learning must take a multimethods approach [40].

The focus on outcomes as a modification of individuals cognitive structures, without changes in cognitive structures, learning cannot have occurred, changes are the key of the transfer of knowledge. Learning outcomes defined as the extent to which an individuals cognitive structures have improved over times, and the focus on three distinct types of instrumental cognitive changes: replication, refers to the propagation at existing cognitive structure, adaptation, refers to incremental change in causal structures, paralleling the ongoing evaluation of work in response to new development. Innovation, refers to radical, discontinuous change [13].

Cognitive processing activities are those thinking activities that students use to process subject matter. They directly lead to learning outcomes in term of knowledge, understanding skills... etc. Affective activities involve emotions that arise during learning and lead to affective states that may positively, neutrally, or negatively influence the progress of learning process, like motivating one self, attributing learning outcomes to causal factors. Regulation activities steer the cognitive and affective activities and therefore, indirectly lead to learning outcomes [33].

In elementary, secondary, and higher education environment, the curriculume and its educational goals and objectives, found in all types of planning and curriculum review documents, determine the desired learning outcomes. Student learning outcomes, are not the only important arena of evaluation. It is equally important to measure and document personal experiences that directly contribute to the development of information literate individuals [40].

Learning outcomes generally identified to be essential for preparing the younger generation for the challenges of life in the knowledge society include the ability and readiness to engage in life long learning, to access and evaluate information, to communicate effectively and to collaborate with others in solving complex open- ended problems, with the appropriate use of technology [32], because there are not only more graduates going on to the job market, but more different types of graduates are being prepared for more diverse occupational specialities. This makes the transition from education to the workplace a more complex and problematic. Therefore, in most countries the role and organization of higher education are being questioned by new student demands and a more competitive environment for universities [41].

The involvement of the graduates working in various institutions in the community will give the university feedback on the success of KM system in the improvement of learning among students, and whether the outcomes of learning are appropriate to the nature of work in these institutions, and whether their expectations are met, their need of specialists in various fields. It is expected that this feedback will play an important role in bringing about the change and the continuous modernization of $\mathrm{KM}$ system at the university so that it constantly remains an effective management system in the management of the learning and education process, leading to maintaining the level of educational outcomes and its excellence so as to serve the community's goals.

\section{REFERENCES}

[1] Y. M. Ch. Yeh, The implementation of knowledge management system in Taiwan's higher education, Journal of College Teaching \& Learning, vol.2 (9), 2005, pp. 35-42.

[2] F. Masdoud, Knowledge management and innovation: the place of Arab universities in these developments. Paper presented at the strategic management seminar in higher education institutions, 18 November 1426H, King Khalid university, Saudi Arabia.

[3] B. F. Mahjoub, Arab Universities Management in the Light of International Standards, Cairo, Egypt: Arab Organization for Administrative Development, 2003.

[4] N. Butcher, Knowledge management strategies for distance education. Retrieved February 9, 2014 from: http://pcf4.dec.uwi.edu/viewpaper.php?id=73\&print=1 
[5] H. H. Belawi and S. A. Hussin, Knowledge Management in Education, Alxendria: Dar Alwafa for Publication, 2007.

[6] B. Cronin, Knowledge management, organizational culture and Anglo-American higher education, Journal of Information Science Vol. 27 (3), 2001, pp.129-137. http://dx.doi.org/10.1177/016 $\underline{555150102700302}$

[7] J. Wedman and F. K. Wang, Knowledge management in higher education: a knowledge repository approach, Journal of Computing in Higher Education vol. 17 (1), 2005, pp. 116-138. http://dx.doi.org/10.1007/BF02960229

[8] Q Geng, Ch. Townley, K. Huang and J. Zhang, Comparative knowledge management: a pilot study of Chinese and American universities, Journal of the American Society for Information Science and Technology vol.56 (10), 2005, pp.1031-1044. http://dx.doi.org/10.1002/asi.20194

[9] Th. Menkhoff, L. Benjamin, R. Chiang and Y. W. Chay, Knowledge management as an enabler affective career services in institutions of higher learning: the case of Singapore management university, International Journal of Human Resource Development \& Management vol. 5(2), 2005, pp. 204-217. http://dx.doi.org/10.1504/IJHRDM.2005.006326

[10] A. AlAli, A. I. Gendilji and G. Omary, Introduction to Knowledge Management, Jordan: Dar Almaseera for Publication, 2006.

[11] M. Sigala and T. Baum, Trends and issues in tourism and hospitality higher education: visioning the future, Tourism and Hospitality Research, vol. 4(4), 2003, pp. 367-376.

[12] Knowledge management system for teaching and learning, Retrieved February 9, 2014 from: http://fiji09.cpsctech.org/.

[13] J. Rowley, Knowledge management in pursuit of learning: the learning with knowledge cycle, Journal of Information Science, vol. 27 (4), 2001, pp. 227-237. http://dx.doi.org/10.1177/016555 150102700406

[14] G. Ellingsen, The role of trust in knowledge management : a case study of physicians at work at the university hospital of northern Norway, Informing Science, 6, 2003, pp.193-208.

[15] S. Numprasertchai and Y. Poovarawan, Improving university performance through ICT based knowledge management system International Journal of Innovation \& Technology Management, vol. 5 (2), 2008, pp.167-178. http://dx.doi.org/10.1142/S02198 $7700800131 \mathrm{X}$

[16] W. H. Vanderburg, The Contemporary university and the poverty of nations: Rethinking the mission of STS, Bulletin of Science,Technology \& Society, vol. 23 (4), 2003, pp. 227-235. http://dx.doi.org/10.1177/0270467603256076

[17] M. W. Blissenden, A reflection on the use of mentoring of early career academics to improve teaching and learning, The International Journal of Learning, vol. 15, (3), 2008, pp.133-138.

[18] . Grygoryev and S. Karapetrovic, Tracking classroom teaching and learning: an SPC application, Quality Engineering, 17, 2005, pp. 405-418. http://dx.doi.org/10.1081/QEN-200059867

[19] D. McManus and B. Loughridge, Corporate information, institutional culture and knowledge management: a UK university Library Perspective, New Library Word, vol. 103 (1180), 2002, pp. 320- 327. http://dx.doi.org/10.1108/03074800210445453

[20] D. M. Zoubi, Knowledge management awareness and it related operations and their impact on knowledge management utilization at Jordanian universities, International Journal of knowledge management, vol.5 (4), 2009, pp. 60-84. http://dx.doi.org/10.4018/ jkm.2009062904

[21] L. Hassell, A continental philosophy perspective on knowledge management, Information System Journal, 17, 2007, pp.185-195. http://dx.doi.org/10.1111/j.1365-2575.2007.00233.x

[22] M. G. Mohayidin, N. Azirawani, M. N. Kamaruddin and M. I. Margono, The application of knowledge management in enhancing the performance of Malaysian universities, Electronic Journal of Knowledge Management, vol. 5 (3), 2007, pp.301-312.

[23] M. Bhusry and J. Ranjan, Enhancing the teaching- learning process: a knowledge management approach, International Journal of Educational Management, vol. 26 (3), 2012, pp. 313-329. http://dx.doi.org/10.1108/09513541211213372

[24] J. A. P Sanchez, Knowledge management in universities, SCIRE: Representacion Organization del Conocimiento, vol. 6 (2), 2001, 99.
[25] Q. Geng, CH. Tawnley, K. Huange and J. Zhang, Comparative knowledge management: a pilot study of Chinese and American universities, Journal of the Society for Information Science and Technology, vol. 56 (10), 2005, pp.1031-1044. http://dx.doi.org/10.1002/asi.20194

[26] P. H. Gray and D. B. Meister, Knowledge Sourcing effectiveness, Management Science, vol. 50 (6), 2004, pp. 821-834. http://dx.doi.org/10.1287/mnsc.1030.0192

[27] T.Smant, Ch. Tomkovich, E. Jones and A. Menson, Undergraduate marketing education in the twenty first century : views from three institutions, Marketing Education Review, vol.9 (1), 1999, pp. $1-10$.

[28] L. F. C. Quiroga, W. A. Moreno and D. Garcia, A model to pedagogically support teaching \& learning scenarios for engineering innovation from a complex systems perspective. Retrieved February 10, 2014 from: Learning Scenarios- innovation- ComplexSystems-KM.pdf-Adobe reader.

[29] F. Saba and D. McDowell, Knowledge management for teachers: $\mathrm{T}$ the collection, organization, and sharing of educational wisdom, Educational Technology, vol. 47 (2), 2007, pp. 39-44.

[30] P. Lefrere, Competing higher education futures in a globalizing world, European Journal of Education, vol. 42 (2), 2007, pp. 201213. http://dx.doi.org/10.1111/j.1465-3435.2007.00301.x

[31] A. Bain and R. J. Parkes, Can schools realize the learning Potential of knowledge management?, Canadian Journal of Learning \&Technology, vol.32 (2), 2006, pp.149-162.

[32] N. Law, Y. Lee and A. Chaw, Practice characteristics that lead to $21^{\text {st }}$ century learning outcomes, Journal of Computer Assisted Learning, 18, 2002, pp. 415-426. http://dx.doi.org/10.1046/j.02664909.2002.00253.doc.X

[33] J. D. Vermunt and Y. T. Vermetten, Patterns in student learning: relationships between learning strategies, conceptions of learning, and learning orientations, Educational Psychology, vol. 16 (4), 2004, pp.359-383. http://dx.doi.org/10.1007/s10648-004-0005-y

[34] H. W. Lee, Contemporary knowledge management platformEPSS, The Journal of American Academy of Business, vol. 7(1), 2005, pp.197-201.

[35] M. Raman, T. Ryan and L. Olfman, Designing knowledge management systems for teaching and learning with wiki technology, Journal of Information Systems Education, vol.16 (3), 2005, pp. 311-320.

[36] SH. Wang and H. Wang, A design thinking approach to teaching knowledge management, Journal of Information Systems Education, vol. 19 (2), 2008, pp.137-139.

[37] CH. K. Davis, Two information technology classroom mini cases: Benefits assessments and implementation issues, Journal of Information Systems Education, vol. 18 (1), 2007, pp.15-20.

[38] J. M. Hanson and K. E. Sinclair, Social constructivist teaching methods in Australian universities- reported uptake and perceived learning effects: a survey of lecturers, Higher Education Research \& Development, vol. 27 (3), 2008, pp.169-186. http://dx.doi.org/10.1080/07294360802183754

[39] L. P. Baldwin, Editorial, Active Learning in Higher Education, vol. 9 (3), 2008, pp.195-199. http://dx.doi.org/10.1177/ 1469787408095845

[40] B.G. Lindouer and G. Columnist, The three arenas of information literacy assessment, Information Literacy and Instruction, vol.44 (2), (2) 2004, pp 122-129.

[41] P. Tynjala, J. Valimaa and A. Sarja, Pedagogical perspectives on the relationships between higher education and working life, Higher Education, vol. 46, 2003, pp. 147-166. http://dx.doi.org/10.1023/A:1024761820500

\section{AUTHOR}

D. M. Al-Zoubi is with the Education Science Department, Irbid University College, Al-balqa Applied University, Irbid 21110, Jordan. (dalalzoubi@yahoo.com).

Submitted 23 February 2014. Published as re-submitted by the author 04 April 2014. 